\title{
New perspectives for the treatment of Hansen's disease
}

DOI: http:/ / dx.doi.org/10.1590/abd1806-4841.2017920601

In the meeting of the World Health Organization (WHO) Expert Committee on Leprosy in 1981, the need for a therapeutic regimen that could solve the growing problem of sulfone-resistant multibacillary patients and the also worrisome perspective of rifampicin and clofazimine resistance were discussed. ${ }^{1}$ From this meeting, arose the recommendation of the combination of dapsone, rifampicin and clofazimine for multibacillary and dapsone and rifampicin to paucibacillary patients. This therapeutic combination, known as Multidrug Therapy (MDT) or Polychemotherapy (PQT), changed the context of Hansen's disease: it broke the dapsone resistance cycle and allowed for the cure of millions of patients.

In view of the excellent results with PQT in the decade of 1980, in 1991 WHO launched the elimination goal for Hansen's disease in all endemic countries until the year of 2000. ${ }^{2}$ Except for Brazil, this goal was achieved in 2005 . The prevalence was reduced to the suggested rate, which is less than 1 leprosy case in 10,000 inhabitants. It was expected that, from this small number of patients in the population, the transmission would be extremely reduced, with gradual disappearance of the condition. ${ }^{3}$

However, the predictions did not materialize. ${ }^{3}$ What we see is that, despite all advances with a marked decrease in the prevalence rates (known registered cases), the incidence did not show significant differences, indicating that transmission was not significantly affected., ${ }^{4,5} 6$
Among the core problems for the treatment and control of Hansen's disease are the need for a classification of the patients, adverse events of the medications and, in particular, the length of treatment: until a negative bacilloscopy is obtained in the initial phases of PQT; then a fixed duration of 24 months and, currently, 12 months.

In Brazil, over the past 14 years, an important clinical essay was developed for the treatment of Hansen's disease with a single regimen of PQT and fixed duration of 6 months, with no need for clinical classification. This study, funded by the Ministério da Saúde/CNPq, was conducted in two national tertiary dermatology centers, accredited by the Brazilian Society of Dermatology (SBD). The project was already finalized, demonstrating that the objectives are feasible and can be implemented in all endemic countries. ${ }^{7,8}$

The use of a single therapeutic regimen, without the need for classification through tests will certainly contribute to a better operationalization of the treatment for patients; however, we still have a long way ahead to reduce the transmission and the number of new patients, with unfortunately a high proportion of deformities.

In the Continuing Medical Education article of this edition we approach the different aspects related to Hansen's disease, including the details related to treatment regimens in the past few decades.

\section{Scientific Editor \\ Sinésio Talhari}

\section{Associate Scientific Editors}

Bernardo Gontijo

Everton Carlos Siviero do Vale

Silvio Alencar Marques

\section{REFERENCES}

1. World Health Organization. Chemotherapy of Leprosy for Control Programmes Report of a WHO Study Group. Geneva; 1982.

2. World Health Organization. The Forty-fourth World Health Assembly. World Health Assembly (WHA) Resolution to Eliminate Leprosy; 1991.

3. Fine PE. Reflections on the elimination of leprosy. Int J Lepr Other Mycobact Dis. 1992;60:71-80.

4. World Health Organization. Weekly epidemiological record, no 35, 2, September 2016.

5. World Health Organization. Global Leprosy Strategy 2016 - 2020: Accelerating Towards a Leprosy-Free World. Geneva; 2016.
6

Talhari S , Grossi MAF, Oliveira MLW, Gontijo B, Talhari C, Penna GO. Hansen's disease: a vanishing disease? Mem Inst Oswaldo Cruz. 2012;107 Suppl 1:13-6.

7. Penna ML, Buhrer-Sekula S, Pontes MA, Cruz R, Goncalves Hde S, Penna GO. Results from the clinical trial of uniform multidrug therapy for leprosy patients in Brazil (U-MDT/CBR): decrease in bacteriological index. Lepr Rev. 2014;85:262-6.

8. Penna GO, Bührer-Sékula S, Kerr LRS, Stefani MMA, Rodrigues LC, de Araújo MG, et al. Uniform Multidrug Therapy for leprosy patients in Brazil (U-MDT/CT-BR): Final results of open label, randomized and controlled clinical trial, among MB patients. PLoS Negl Trop Dis. 2017;11:e0005725. 